\title{
Recent Insights into Experimental Mouse Models of Diabetic Nephropathy
}

\author{
Gregory H. Tesch ${ }^{\mathrm{a}, \mathrm{b}}$ David J. Nikolic-Paterson ${ }^{\mathrm{a}, \mathrm{b}}$ \\ ${ }^{\mathrm{a}}$ Department of Nephrology and ${ }^{\mathrm{b}}$ Monash University Department of Medicine, Monash Medical Centre, \\ Clayton, Australia
}

\section{Key Words}

Mouse models · Diabetic nephropathy · C57BL/6 •

Streptozotocin $\cdot \mathrm{db} / \mathrm{db} \cdot$ Advanced glycation end

products $\cdot$ Oxidative stress $\cdot$ Fibrosis

\begin{abstract}
Background/Aims: Mouse models are an essential experimental tool for investigating the role of molecular mechanisms and genetic susceptibility in the development of diabetic nephropathy. Methods: The most widely used inbred strain, the C57BL/6 mouse, is commonly used in streptozotocin-induced models of type 1 diabetes and is particularly susceptible to obesity-induced type 2 diabetes. However, use of this strain has been criticised by studies suggesting that it is relatively resistant to renal injury. Results: Recent refinement of these models and utilisation of genetically modified (knockout and transgenic) mice on a $\mathrm{C} 57 \mathrm{BL} / 6$ background has provided important insights into the roles of oxidative stress, advanced glycation end products, inflammation and profibrotic mechanisms in the development of type 1 and type 2 diabetic nephropathy. Conclusion: These findings demonstrate the utility of mouse models for identifying and testing novel therapeutic strategies which could translate into better protection against the human disease.
\end{abstract}

\section{KARGER}

Fax +4161306 1234 E-Mail karger@karger.ch www.karger.com

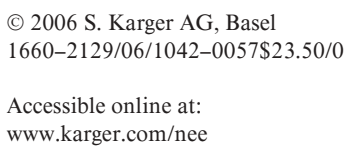
www.karger.com/nee

\section{Introduction}

Diabetic nephropathy is the single major cause of endstage renal failure in the USA and Europe [1]. Despite current treatments, involving glycaemic and blood pressure control, many diabetic patients are still prone to developing kidney failure [2]. Consequently there is an urgent need to identify additional therapeutic strategies, and this will require a greater understanding of the pathogenic mechanisms responsible for the development of diabetic nephropathy.

A variety of mouse models provide valuable insight into the genetic factors which confer risk of developing diabetic nephropathy. They can also be used to identify the pathogenic importance of specific molecular mechanisms in promoting disease and may serve as a useful platform for testing novel therapeutic strategies. Nephropathy in humans is normally a late complication of diabetes, occurring in susceptible patients after 10-20 years of diabetes [1]. Consequently mouse diabetic models need to be maintained for extended periods after the onset of hyperglycaemia, usually 3-8 months, in order to detect substantial renal injury, and glomerular and tubulointerstitial lesions. The major limitations currently seen in many mouse models are a lack of observed hypertension, an inability to measure a decline in renal function and the absence of advanced pathological lesions [3]. Progress in overcoming the first two of these problems is

Dr. David Nikolic-Paterson

Department of Nephrology, Monash Medical Centre, 246 Clayton Road

Clayton, Victoria 3168 (Australia)

Tel. +61 39594 3535, Fax +61395946530

E-Mail David.Nikolic-Paterson@med.monash.edu.au 
now being made using more sophisticated detection techniques, including radiotelemetry to measure intra-arterial blood pressure, HPLC to measure mouse creatinine clearance and inulin clearance assays to assess glomerular filtration rate [3]. Severer kidney lesions in diabetic mice are now being achieved by prolonging the duration of diabetes and by altering mouse genetic characteristics to make them more susceptible to diabetic injury [3].

Most studies of mouse diabetic nephropathy are performed in C57BL/6 mice. These mice breed well, have long lifespans, are highly susceptible to the induction of diabetes and are available with a wide range of monogenetic mutations and transgenic modifications. This review focuses on the recent diabetic nephropathy studies performed on mice with a C57BL/6 genetic background. Recent information on diabetic nephropathy in other mouse strains are described elsewhere [3-5]. In addition, the development of diabetic nephropathy in rat models, and their comparison to mouse models, has been detailed in previous reviews $[4,6,7]$.

\section{Models Resulting from Primary Insulin Deficiency}

Streptozotocin (STZ), an analogue of N-acetylglucosamine, is widely used to create rodent models of type 1 diabetic nephropathy. STZ is readily transported into pancreatic $\beta$-cells by glucose transporter 2 and causes $\beta$ cell toxicity by inhibiting the activity of $\beta$-cell $\mathrm{N}$-acetyl$D$-glucosaminidase, resulting in insulin deficiency [8]. At high doses in mice $(\geq 200 \mathrm{mg} / \mathrm{kg})$ STZ induces almost immediate hyperglycaemia. However, these high doses have been shown to promote non-specific cytotoxicity resulting in acute kidney tubular damage [9]. Consequently a problem associated with diabetic nephropathy models employing high-dose STZ is that the developing nephropathy results from hyperglycaemia-induced injury superimposed on acute renal STZ cytotoxicity, making it difficult to interpret any findings [9].

The effects of non-specific STZ cytotoxicity can be reduced to a negligible level by inducing diabetes with multiple injections of lower doses of STZ. Diabetic nephropathy studies have been performed in mice with multiple STZ doses $(5 \times 40-55 \mathrm{mg} / \mathrm{kg})$ or $(2 \times 100-125 \mathrm{mg} / \mathrm{kg})$ given by intraperitoneal injection on consecutive days with sustainable hyperglycaemia appearing within 2 weeks after the first STZ injection [5, 10, 11]. Recent work using an STZ regimen of $5 \times 40 \mathrm{mg} / \mathrm{kg}$ per day has shown a hierarchical response in the susceptibility of inbred strains to development of hyperglycaemia (DBA/2 > C57BL/6 > MRL/MP > 129/Sv > BALB/c) [12]. Therefore it is important to establish a strain-appropriate STZ dosage protocol for achieving hyperglycaemia before embarking on a major study of diabetic nephropathy using this model.

The development of STZ-induced diabetic nephropathy in susceptible mouse strains is dependent on the level and duration of hyperglycaemia with histological lesions developing both in glomeruli (hypertrophy, inflammation, glomerular basement membrane thickening, fibrosis) and the tubulointerstitium (tubular atrophy and apoptosis, inflammation, myofibroblast accumulation, fibrosis), resulting in a progression to mild albuminuria and increased serum creatinine, usually between 12 and 35 weeks of disease $[5,10,13]$. STZ-diabetic nephropathy is more pronounced in male compared to female C $57 \mathrm{BL} / 6$ mice and progresses more rapidly if these mice are deficient in apolipoprotein E (ApoE), a molecule responsible for the clearance of plasma lipoproteins [13]. ApoE knockout mice have increased circulating levels of cholesterol and triglycerides, which promotes a susceptibility to atherosclerosis. The increased severity of diabetic nephropathy and albuminuria in ApoE-/- compared to wild-type C57BL/6 mice has resulted in the recent preferred use of this strain in studies examining therapeutic intervention in mouse STZ-diabetic nephropathy [14].

An alternative genetic model of type 1 diabetes on the C57BL/6 background is insulin-2 Akita mutant mouse strain (Ins2 ${ }^{\text {Akita }}$ ) [3]. These mice exhibit a misfolding of insulin-2, which results in pancreatic $\beta$-cell selective proteotoxicity and islets which are largely depleted of $\beta$-cells [3]. Heterozygous mutant mice are fertile and develop hypoinsulinaemia, hyperglycaemia, polydipsia and polyuria at 3-4 weeks of age, with hyperglycaemia being substantially worse in males. Homozygous mutant mice are growth retarded and die within 1-2 months of birth. Some distinct features of diabetic nephropathy in male Ins $2^{\text {Akita }}$ mice include mild hypertension and increased glomerular pathology and albuminuria compared to STZtreated wild-type male C57BL/6 mice [12]. However, these findings may reflect a severer hyperglycaemia seen in the Ins $2^{\text {Akita }}$ mice used for comparison. A recent study has also demonstrated that podocyte apoptosis and depletion increase sharply with the onset of hyperglycaemia in Ins $2^{\text {Akita }}$ mice and coincide with the appearance of albuminuria [15]. 


\section{Models Resulting from Primary Insulin Resistance}

C57BL/6 mice are highly susceptible to obesity-induced insulin resistance resulting from a high-fat diet or genetic mutations in leptin (ob/ob mice) or the leptin receptor (db/db mice) [3, 4]. Of these models only the $\mathrm{db} / \mathrm{db}$ mouse develops significant diabetic nephropathy. On a pure C57BL/6 background approximately $50 \%$ of male $\mathrm{db} / \mathrm{db}$ mice with unrestricted access to a normal diet will develop overt diabetes (non-fasting blood glucose $>16 \mathrm{mM}$ ), and these mice display a marked increase in albuminuria and plasma creatinine between the age of 6 and 8 months [16]. This C57BL/6 db/db strain has been successfully intercrossed with gene knockout and transgenic mice on a C57BL/6 background, and these new strains have been used to identify mechanisms of inflammation and oxidative stress involved in the development of diabetic nephropathy $[17,18]$.

Studies of diabetic nephropathy in $\mathrm{db} / \mathrm{db}$ mice are more commonly performed with the C57BLKS strain, which has $84 \%$ homology with the C57BL/ 6 strain and $16 \%$ of alleles shared with the DBA/2 strain [19]. These mice develop similar degrees of hyperphagia and weight gain to the C57BL/6 strain, but have an accelerated development of hyperglycaemia with around $100 \%$ incidence of overt diabetes in males at 10 weeks of age [19]. This difference is thought to be due to a more rapid degeneration of islet cells in the C57BLKS strain [19]. The C57BLKS db/db model develops marked albuminuria by week 12 [20] and a 2-fold increase in plasma creatinine at week 16 [21]. This model shows a rapid progression in the development of renal injury and histopathology and is particularly suited to studies which test novel intervention therapies for the treatment of established diabetic nephropathy.

There are some special considerations to be noted when studying C57BL/6 and C57BLKS $\mathrm{db} / \mathrm{db}$ mouse models. $\mathrm{db} / \mathrm{db}$ mice develop marked hyperinsulinaemia during the onset of obesity and type 2 diabetes. However, islet degeneration develops as the disease progresses so that the blood insulin levels decline and animals may require insulin treatment for survival [19]. This feature is often indicated by extremely high blood glucose readings $(>35 \mathrm{mM})$ in conjunction with an observed weight loss occurring in C57BKS $\mathrm{db} / \mathrm{db}$ mice after 18 weeks and C57BL/ $6 \mathrm{db} / \mathrm{db}$ mice after 24 weeks (authors' observations). A further consideration is the validity of serum creatinine measurements as a reflection of renal function in obese $\mathrm{db} / \mathrm{db}$ mice. Obese mice have diminished muscle mass due to a lack of exercise, and this will reduce the level of serum creatinine associated with normal renal function. Consequently serum creatinine measurements are likely to underscore the actual decline in renal function in $\mathrm{db} / \mathrm{db}$ mice with diabetic nephropathy [17]. Therefore we recommend that future studies use alternative techniques (e.g. inulin-FITC clearance [3]) for assessing renal function in $\mathrm{db} / \mathrm{db}$ mice.

\section{Advanced Glycation End Products: Role of Receptor Interaction}

Accumulation of advanced glycation end products (AGEs) in the diabetic kidney is associated with the development of nephropathy. Compounds which inhibit the formation of AGEs have been shown to suppress the development of diabetic nephropathy in the STZ-treated ApoE-/- C57BL/6 mice [13] and C57BLKS db/db mice [20]. Recent mouse studies have indicated that interaction with the receptor for AGEs (RAGE) is necessary for the renal damaging effects of AGEs. Treatment with antiRAGE antibody [22] or soluble RAGE [23] is protective against the progression of diabetic nephropathy in C57BLKS db/db mice. Similarly RAGE-deficient mice (C57BL/6 x 129/Sv) develop less severe glomerular injury after STZ-induction of diabetes compared to wildtype controls [23]. These findings suggest that therapeutic blockade of AGE formation and AGE-induced responses are critical targets for treating diabetic nephropathy.

\section{Oxidative Stress: Role of Antioxidant Enzymes}

Renal oxidative stress has been implicated in the pathogenesis of diabetic nephropathy. Excess renal production of reactive oxygen species (ROS), including superoxide, hydrogen peroxide and peroxynitrate, is thought to promote damage by altering protein structures and activating signalling pathways linked to cell injury. Accumulation of kidney ROS is regulated by antioxidants and kidney antioxidant enzymes, including NADPH oxidase, superoxide dismutase, catalase, glutathione peroxidase (GPx), thioredoxin and peroxiredoxins $[18,11]$. The impact of dietary and synthetic antioxidants on diabetic nephropathy has been investigated primarily in rat models, whereas the role of antioxidant enzymes has been largely determined in mice. Systemic inhibition of NADPH oxidase with apocynin treatment has been shown to suppress diabetic renal injury in 
C57BLKS db/db mice [15]. Studies in transgenic strains overexpressing SOD-1 demonstrated that this enzyme reduces renal oxidative stress and inhibits the development of nephropathy in STZ diabetes and C57BL/6 db/db mice $[24,18]$. In comparison Gpx 1 is not protective against STZ-induced diabetic nephropathy [11], and transgenic mice overexpressing Gpx 1 develop insulin resistance, suggesting that this enzyme interferes with insulin function by overquenching intracellular ROS required for insulin sensitising [25]. These experimental findings suggest that oxidative stress contributes to diabetic nephropathy. However, its role appears complex, and specifically blocking ROS pathways in patients should be treated with caution.

\section{Inflammation: Role of Macrophages}

Renal inflammation is a characteristic of diabetic nephropathy in mice and humans $[10,16,26]$. Studies in STZ-treated and db/db mice with a C57BL/6 background have shown that infiltrating leucocytes in diabetic kidneys consist almost entirely of macrophages and correlate with the development of hyperglycaemia and the increased renal expression of macrophage chemokines [6, 12]. Macrophage activation is also seen in diabetic kidneys [16, 26, 27], suggesting that these macrophages may be a source of reactive oxygen species and cytokines. A role for macrophages in mouse diabetic nephropathy was first indicated in a study which examined the impact of intercellular adhesion molecule-1 deficiency on STZ-induced diabetes [28]. A reduction in kidney macrophage accumulation and renal pathology was evident at 6 months after STZ treatment. However, these results are controversial, since the model was induced with a single high dose of STZ $(200 \mathrm{mg} / \mathrm{kg})$, which is known to cause acute renal cytotoxicity. Subsequent studies in intercellular adhesion molecule-1-deficient C57BL/6 db/db mice and monocyte chemoattractant protein-1-deficient C57BL/6 mice, made diabetic with multiple lower doses of STZ, have confirmed that significant reductions in kidney macrophages result in a marked decline in albuminuria, histological damage and renal fibrosis [17, 27]. These latter studies also showed that macrophages stimulated with high glucose or AGEs can promote proinflammatory and profibrotic responses.

\section{Fibrosis: Role of Profibrotic Cytokines}

Glomerulosclerosis and tubulointerstitial fibrosis are hallmarks of advanced diabetic nephropathy. These prominent features arise from an accumulation of myofibroblasts and extracellular matrix in the diabetic kidney. Myofibroblast accumulation in mouse STZ-diabetic nephropathy appears to be partly dependent on local cell proliferation, which can be induced by growth factors (IL1 and PDGF) released during inflammation [10]. Administration of a PDGF receptor kinase inhibitor (Imatinib, STI-571) has been shown to ameliorate STZ-diabetic nephropathy in ApoE-/- mice, which include reductions in cell proliferation, myofibroblast accrual and collagen deposition [14]. This suggests that growth factors could be therapeutically targeted to inhibit myofibroblast accumulation in diabetic nephropathy.

TGF- $\beta$ appears to play a central role in the profibrotic responses occurring in kidney cells during diabetes. Treatment with a neutralising TGF- $\beta$ mAb has been shown to suppress the increase of renal matrix mRNAs in diabetic nephropathy in STZ-treated and db/db mice $[29,21]$. C57BL/ 6 mice heterozygous for the TGF- $\beta$ type 2 receptor, which have decreased TGF- $\beta$-induced SMAD signalling, are similarly protected from fibrosis in STZ-diabetic nephropathy [30]. In addition mice with genetic deficiencies of SPARC (secreted protein, acidic and rich in cysteine) or PAI-1 (plasminogen activator inhibitor-1) also show reduced fibrosis following STZ induction of diabetes, which is associated with their reduced renal production of TGF- $\beta[31,32]$. Recently therapeutic studies have demonstrated that renal fibrosis in $\mathrm{db} / \mathrm{db}$ mice can be suppressed by drugs which inhibit TGF- $\beta$ induction of SMAD2/3 or p38 MAPK signalling [33, 34]. This latter approach of inhibiting specific TGF- $\beta$ signalling pathways may prove more appropriate for targeting the profibrotic actions of TGF- $\beta$, since total TGF- $\beta$ blockade can have detrimental consequences on the regulation of inflammation and tumour suppression.

\section{Conclusions}

Mouse models of diabetic nephropathy mimic many of the structural and biochemical features of diabetic renal injury, but do not fully reproduce the human disease. The studies described in this review indicate that mice with a C57BL/6 background are a valuable tool for examining the pathogenic mechanisms of type 1 and type 2 diabetic nephropathy, particularly because of the avail- 
ability of many monogenetic mutations and transgenic modifications on this strain. The use of these mice has provided important information about the role of AGEs, antioxidant enzymes, macrophages and profibrotic cytokines in the development of diabetic nephropathy. Such approaches hold promise as a means to identify additional human therapies for future clinical use.

\section{Acknowledgements}

The authors and part of the work described in the review were funded by grants from the National Health and Medical Research Council of Australia and the Diabetes Australia Research Trust.

\section{References}

1 Molitch ME, DeFronzo RA, Franz MJ, Keane WF, Mogensen CE, Parving HH, Steffes MW, American Diabetes Association: Nephropathy in diabetes. Diabetes Care 2004;27(suppl 1): S79-S83.

-2 Svensson M, Sundkvist G, Arnqvist HJ, Bjork E, Blohme G, Bolinder J, Henricsson M, Nystrom L, Torffvit O, Waernbaum I, Ostman J, Eriksson JW: Signs of nephropathy may occur early in young adults with diabetes despite modern diabetes management: results from the nationwide population-based Diabetes Incidence Study in Sweden (DISS). Diabetes Care 2003;26:2903-2909.

3 Breyer MD, Bottinger E, Brosius FC 3rd, Coffman TM, Harris RC, Heilig CW, Sharma K: AMDCC: mouse models of diabetic nephropathy. J Am Soc Nephrol 2005; 16:27-45.

$\checkmark 4$ Allen TJ, Cooper ME, Lan HY: Use of genetic mouse models in the study of diabetic nephropathy. Curr Atheroscler Rep 2004; 6:197202.

$\checkmark 5$ Qi Z, Fujita H, Jin J, Davis LS, Wang LS, Wang Y, Fogo AB, Breyer MD: Characterization of susceptibility of inbred mouse strains to diabetic nephropathy. Diabetes 2005;54: 2628-2637.

-6 Janssen U, Phillips AO, Floege J: Rodent models of nephropathy associated with type II diabetes. J Nephrol 1999:12;159-172.

7 Schrijvers BF, De Vriese AS, Flyvbjerg A: From hyperglycemia to diabetic kidney disease: the role of metabolic, hemodynamic, intracellular factors and growth factors/cytokines. Endocr Rev 2004:25;971-1010.

$>8$ Konrad RJ, Mikolaenko I, Tolar JF, Liu K, Kudlow JE: The potential mechanism of the diabetogenic action of streptozotocin: inhibition of pancreatic $\beta$-cell O-GlcNAc-selective $\mathrm{N}$-acetyl- $\beta$ - $D$-glucosaminidase. Biochem J 2001;356:31-41.

>9 Tay YC, Wang Y, Kairaitis L, Rangan GK, Zhang C, Harris DC: Can murine diabetic nephropathy be separated from superimposed acute renal failure? Kidney Int 2005;68:391398.

10 Chow FY, Nikolic-Paterson DJ, Atkins RC, Tesch GH: Macrophages in streptozotocin-induced diabetic nephropathy: potential role in renal fibrosis. Nephrol Dial Transplant 2004; 19:2987-2996.
11 De Haan JB, Stefanovic N, Nikolic-Paterson DJ, Scurr LL, Croft KD, Mori TA, Hertzog P, Kola I, Atkins RC, Tesch GH: Kidney expression of glutathione peroxidase- 1 is not protective against streptozotocin-induced diabetic nephropathy. Am J Physiol Renal Physiol 2005;28:F544-F551.

12 Gurley SB, Clare SE, Snow KP, Hu A, Meyer TW, Coffman TM: Impact of genetic background on nephropathy in diabetic mice. Am J Physiol Renal Physiol 2006;290:F214F222.

13 Lassila M, Seah KK, Allen TJ, Thallas V, Thomas MC, Candido R, Burns WC, Forbes JM, Calkin AC, Cooper ME, Jandeleit-Dahm KA: Accelerated nephropathy in diabetic apolipoprotein E-knockout mouse: role of advanced glycation end products. J Am Soc Nephrol 2004; 15:2125-2138.

14 Lassila M, Jandeleit-Dahm KA, Seah KK, Smith CM, Calkin AC, Allen TJ, Cooper ME: Imatinib attenuates diabetic nephropathy in apolipoprotein E-knockout mice. J Am Soc Nephrol 2005;16:363-373.

15 Susztak K, Raff AC, Schiffer M, Bottinger EP: Glucose-induced reactive oxygen species cause apoptosis of podocytes and podocyte depletion at the onset of diabetic nephropathy. Diabetes 2006;55:225-233.

16 Chow F, Ozols E, Nikolic-Paterson DJ, Atkins RC, Tesch GH: Macrophages in mouse type 2 diabetic nephropathy: correlation with diabetic state and progressive renal injury. Kidney Int 2004; 65:116-128.

17 Chow FY, Nikolic-Paterson DJ, Ozols E, Atkins RC, Tesch GH: ICAM-1 deficiency is protective against nephropathy in type 2 diabetic $\mathrm{db} / \mathrm{db}$ mice. J Am Soc Nephrol 2005;16:17111722 .

18 DeRubertis FR, Craven PA, Melhem MF, Salah EM: Attentuation of renal injury in $\mathrm{db} /$ $\mathrm{db}$ mice overexpressing superoxide dismutase: evidence for reduced superoxide-nitric oxide interaction. Diabetes 2004;53:762-768.

19 Kumar S, McCue P, Dunn SR: Diabetic kidney disease in the db/db mouse. Am J Physiol Renal Physiol 2003;284:F1138-F1144.

20 Cohen MP, Masson N, Hud E, Ziyadeh F, Han DC, Clements RS: Inhibiting albumin glycation ameliorates diabetic nephropathy in the db/db mouse. Exp Nephrol 2000;8:135-143.
21 Ziyadeh FN, Hoffman BB, Han DC, IglesiasDe La Cruz MC, Hong SW, Isono M, Chen S, McGowan TA, Sharma K: Long-term prevention of renal insufficiency, excess matrix gene expression, and glomerular mesangial matrix expansion by treatment with monoclonal antitransforming growth factor-beta antibody in $\mathrm{db} / \mathrm{db}$ diabetic mice. Proc Natl Acad Sci USA 2000;97:8015-8020.

22 Flyvbjerg A, Denner L, Schrijvers BF, Tilton RG, Mogensen TH, Paludan SR, Rasch R: Long-term renal effects of a neutralizing RAGE antibody in obese type 2 diabetic mice. Diabetes 2004;53:166-172.

23 Wendt TM, Tanji N, Guo J, Kislinger TR, Qu W, Lu Y, Bucciarelli LG, Rong LL, Moser B, Markowitz GS, Stein G, Bierhaus A, Liliensiek B, Arnold B, Nawroth PP, Stern DM, D'Agati VD, Schmidt AM: RAGE drives the development of glomerulosclerosis and implicates podocyte activation in the pathogenesis of diabetic nephropathy. Am J Pathol 2003;162: 1123-1137.

24 Craven PA, Melhem MF, Phillips SL, DeRubertis FR: Overexpression of $\mathrm{Cu} 2+/ \mathrm{Zn} 2+$ superoxide dismutase protects against early diabetic glomerular injury in transgenic mice. Diabetes 2001;50:2114-2125.

25 McClung JP, Roneker CA, Mu W, Lisk DJ, Langlais P, Liu F, Lei XG: Development of insulin resistance and obesity in mice overexpressing cellular glutathione peroxidase. Proc Natl Acad Sci USA 2004;101:8852-8857.

26 Adhikary L, Chow F, Nikolic-Paterson DJ, Stambe C, Dowling J, Atkins RC, Tesch GH: Abnormal p38 mitogen-activated protein kinase signalling in human and experimental diabetic nephropathy. Diabetologia 2004;47:12101222.

27 Chow FY, Nikolic-Paterson DJ, Ozols E, Atkins RC, Rollins BJ, Tesch GH: Monocyte chemoattractant protein-1 promotes diabetic renal injury in streptozotocin-treated mice. Kidney Int 2006;69:73-80.

28 Okada S, Shikata K, Matsuda M, Ogawa D, Usui H, Kido Y, Nagase R, Wada J, Shikata Y, Makino H: Intercellular adhesion molecule-1deficient mice are resistant against renal injury after induction of diabetes. Diabetes 2003;52: 2586-2593. 
29 Sharma K, Jin Y, Guo J, Ziyadeh FN: Neutralization of TGF-beta by anti-TGF-beta antibody attenuates kidney hypertrophy and the enhanced extracellular matrix gene expression in STZ-induced diabetic mice. Diabetes 1996; 45:522-530.

>30 Kim HW, Kim BC, Song CY, Kim JH, Hong HK, Lee HS: Heterozygous mice for TGFbeta-IIR gene are resistant to the progression of streptozotocin-induced diabetic nephropathy. Kidney Int 2004;66:1859-1865.
31 Taneda S, Pippin JW, Sage EH, Hudkins KL, Takeuchi Y, Couser WG, Alpers CE: Amelioration of diabetic nephropathy in SPARC-null mice. J Am Soc Nephrol 2003;14:968-980.

32 Nicholas SB, Aguiniga E, Ren Y, Kim J, Wong J, Govindarajan N, Noda M, Wang W, Kawano Y, Collins A, Hsueh WA: Plasminogen activator inhibitor-1 deficiency retards diabetic nephropathy. Kidney Int 2005;67:12971307.
3 Shibuya K, Kanasaki K, Isono M, Sato H, Omato M, Sugimoto T, Araki S, Isshiki K, Kashiwagi A, Haneda M, Koya D: N-acetylseryl-aspartyl-lysyl-proline prevents renal insufficiency and mesangial matrix expansion in diabetic db/db mice. Diabetes 2005;54:838845.

34 Sugaru E, Nakagawa T, Ono-Kishino M, Nagamine J, Tokunaga T, Kitoh M, Hume WE, Nagata R, Taiji M: SMP-534 ameliorates progression of glomerular fibrosis and urinary albumin in diabetic db/db mice. Am J Physiol Renal Physiol DOI:10.1152/ajprenal.00357. 2005. 